\title{
Electrical characterization of defects introduced during metallization processes in n-type germanium
}

\author{
F.D. Auret* , S.M.M. Coelho, P.J. Janse van Rensburg, C. Nyamhere, W.E. Meyer \\ Physics Department, University of Pretoria, Pretoria 0002, South Africa
}

\section{A R T I C L E I N F O}

Keywords:

$\mathrm{Ge}$

Metallization

Defects

Deep-level transient spectroscopy

DLTS

\begin{abstract}
A B S T R A C T
We have studied the defects introduced in n-type Ge during electron beam deposition (EBD) and sputter deposition (SD) by deep-level transient spectroscopy (DLTS) and evaluated their influence on the rectification quality of Schottky contacts by current-voltage $(I-V)$ measurements. $I-V$ measurements demonstrated that the quality of sputter-deposited diodes are poorer than those of diodes formed by EBD. The highest quality Schottky diodes were formed by resistive evaporation that introduced no defects in Ge. In the case of EBD of metals the main defect introduced during metallization was the $\mathrm{V}-\mathrm{Sb}$ complex, also introduced during by electron irradiation. The concentrations of the EBD-induced defects depend on the metal used: metals that required a higher electron beam intensity to evaporate, e.g. Ru, resulted in larger defect concentrations than metals requiring lower electron beam intensity, e.g. Au. All the EBD-induced defects can be removed by annealing at temperatures above $325^{\circ} \mathrm{C}$. Sputter deposition introduces several electrically active defects near the surface of Ge. All these defects have also been observed after high-energy electron irradiation. However, the $\mathrm{V}-\mathrm{Sb}$ centre introduced by EBD was not observed after sputter deposition. Annealing at $250{ }^{\circ} \mathrm{C}$ in Ar removed all the defects introduced during sputter deposition.
\end{abstract}

(c) 2008 Elsevier Ltd. All rights reserved.

\section{Introduction}

The low effective mass of holes in Ge has opened up the possibility of using Ge in ultrafast complimentary metal-oxide-semiconductor (CMOS) devices [1]. This, in turn, has triggered renewed interest in the properties of defects in Ge because defects ultimately determine the performance of devices. In a detailed study of proton and electron-irradiated $\mathrm{Ge}$ a comparison was made to previously observed radiation-induced defects and level assignments of the E-centre (V-Sb), A-centre (V-O) and divacancy $(\mathrm{V}-\mathrm{V})$ were proposed [2]. Several other O- and Sb-related defects were characterised in O-doped and Sbdoped Ge, respectively. It was also convincingly demonstrated that the E-centre in Sb-doped Ge can be present in

\footnotetext{
* Corresponding author. Tel.: +27124202684; fax: +27123625288.

E-mail address: danie.auret@up.ac.za (F.D. Auret).
}

three charge states and the level positions associated with these levels' states were determined [3-5].

Metallization is a critical processing step in the semiconductor industry. Resistive evaporation, electron beam deposition (EBD) and sputter deposition are commonly used metallization methods. It is well known that resistive evaporation does not introduce any detectable defects in the semiconductor. However, it cannot easily deposit high melting point materials e.g. W or Ru. EBD, on the other hand, is useful to deposit high melting point metals at very controllable rates. Sputter deposition can also be used to deposit high melting point metals and is further capable of stoichiometrically depositing alloys from compound targets. Unfortunately, these latter two methods introduce defects in semiconductors. Some investigations regarding the defects introduced in $\mathrm{Ge}$ during EBD [6-8] and sputter deposition [9,10] have been reported. The defects introduced during these processes reside in the Ge at and close to the metal-Ge junction; 
they influence device performance and alter the barrier heights of the contacts [11]. The defects responsible for these barrier adjustments are formed when energetic particles reach the semiconductor surface and interact with the semiconductor. Depending on the application, these defects may either be beneficial or detrimental to optimum device functioning. For $\mathrm{Si}$ it has been shown that the defects introduced during high-energy electron and proton irradiation increase the switching speed of devices [12].

In this study, we review the electronic properties of defects introduced in n-type Ge during EBD and sputter deposition of different metal Schottky contacts. We also show that the concentrations of the most prominent EBDinduced defect, the $\mathrm{V}-\mathrm{Sb}$ centre, depended on the metal deposited by EBD via the melting point of the metal and the influence thereof on the vacuum during metallization. We have found that sputter deposition also introduces several electrically active defects near the surface of $\mathrm{Ge}$, but, contrary to what has been reported elsewhere [9], it did not introduce the $\mathrm{V}-\mathrm{Sb}$ centre in our experiments. Most of the defects introduced by EBD and sputter deposition have also been observed after high-energy electron irradiation. We also illustrate the effect of these process-induced defects on the current-voltage $(I-V)$ characteristics of the Schottky diodes at different temperatures. Finally, we compare the removal of these metallization-induced defects by thermal annealing.

\section{Experimental procedure}

The Schottky barrier diodes for this study were fabricated on bulk-grown (111) n-type Ge doped with $\mathrm{Sb}$ to a level of $2.5 \times 10^{15} \mathrm{~cm}^{-3}$. Before metallization the samples were first degreased and then etched in a mixture of $\mathrm{H}_{2} \mathrm{O}_{2}: \mathrm{H}_{2} \mathrm{O}(1: 5)$ for $1 \mathrm{~min}$. Directly after cleaning they were inserted into a vacuum chamber where AuSb $(0.6 \%$ $\mathrm{Sb})$ was deposited on their back surfaces. The samples were then annealed at $350^{\circ} \mathrm{C}$ in Ar for $10 \mathrm{~min}$, yielding ohmic contacts with a low contact resistivity. Before Schottky contact deposition, the samples were again chemically cleaned as described above. Metal (Au, Ti and $\mathrm{Ru}$ ) contacts, $0.6 \mathrm{~mm}$ in diameter and $200 \mathrm{~nm}$ thick, were deposited onto the $\mathrm{Ge}$ in an EBD system through a mechanical mask. A Varian $10 \mathrm{kV}$ electron gun vacuum evaporation system was used for this process. In this system, the samples are positioned about $0.4 \mathrm{~m}$ above the electron gun. In a different system Au Schottky contacts were sputter deposited onto similar Ge samples cut from the same wafer. For sputter deposition Ar was leaked into the system to a pressure of $6 \times 10^{-2} \mathrm{mbar}$ [9]. The sputterdeposited contacts were deposited at a rate of about $2 \mathrm{~nm} \mathrm{~s}^{-1}$ and were $400 \mathrm{~nm}$ thick. "Control" Au Schottky contacts were deposited on samples cut from the same wafer by resistive evaporation.

Following contact fabrication, current-voltage $(I-V)$ and capacitance-voltage $(C-V)$ measurements were performed to assess the quality of the diodes and to determine the free carrier density of the Ge, respectively. Thereafter both conventional and high-resolution Laplace deep-level transient spectroscopy (DLTS) $[13,14]$ was used to study the defects introduced in the Ge during the EBD and SD processes. The activation energies, $E_{\mathrm{T}}$, and apparent capture cross sections for electrons, $\sigma_{\text {na }}$, and holes, $\sigma_{\mathrm{pa}}$, (i.e. the DLTS "signatures") of the processinduced electron traps were determined from the conventional DLTS Arrhenius plots. In order to identify the defects introduced by the deposition processes, a comparison was made with defects introduced by high-energy $(\mathrm{MeV})$ electron irradiation from a $\mathrm{Sr}^{90}$ source in samples cut from the same wafer.

\section{Results and discussion}

\subsection{I-V characteristics of Schottky diodes fabricated by EBD and sputter deposition}

$I-V$ measurements were recorded at room temperature as well as at several other lower temperatures. The series resistances of the control diodes remained in the 10-20 $\Omega$ range in the entire temperature regime investigated, indicating that the AuSb back contacts retained their ohmic character, even down to $16 \mathrm{~K}$, the lowest temperature attainable in our cryostat. Room temperature $C-V$ measurements yielded the free carrier density of the Ge as $(2.5 \pm 0.05) \times 10^{15} \mathrm{~cm}^{-3}$. In Fig. 1, we compare the forward and reverse $I-V$ characteristics of Au Schottky contacts formed by resistive evaporation, EBD and sputter deposition at room temperature and at $100 \mathrm{~K}$. We chose $100 \mathrm{~K}$ as

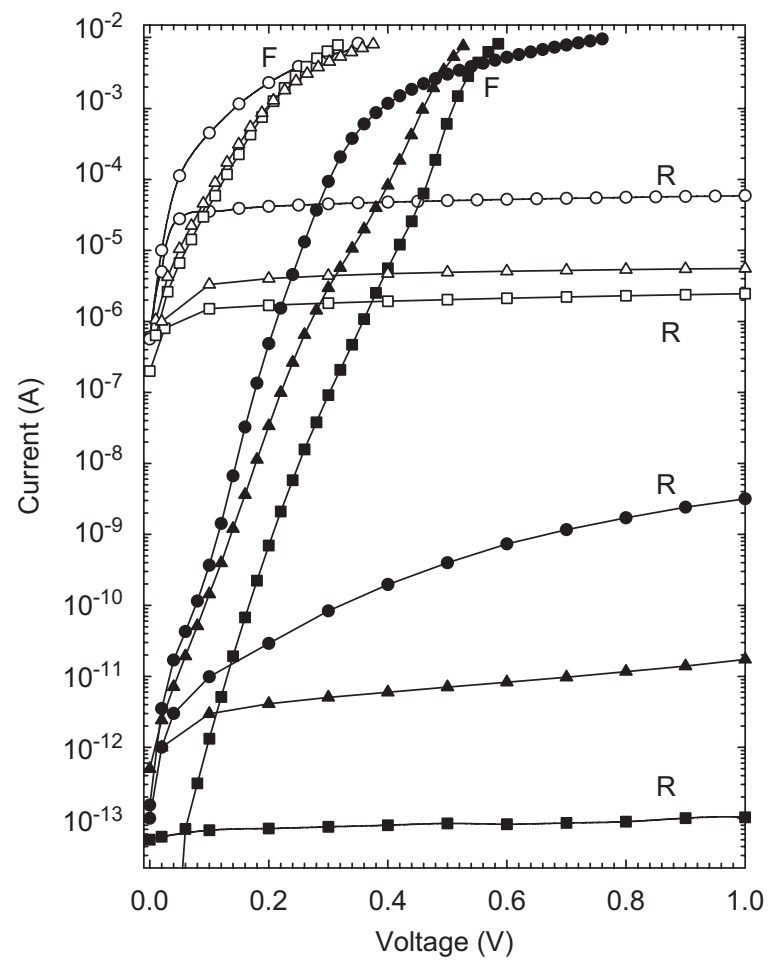

Fig. 1. $I-V$ characteristics of Au Schottky contacts to n-Ge deposited by resistive evaporation (squares), EBD (triangles) and sputter deposition (circles). Open symbols are the data recorded at room temperature while filled symbols represent the data recorded at $100 \mathrm{~K}$. 
the lower temperature because at $100 \mathrm{~K}$ the reverse leakage current of the best diodes (deposited by resistive evaporation) is between $10^{-13}$ and $10^{-14} \mathrm{~A}$, which is the lowest current our equipment can accurately measure. At room temperature the $I-V$ barrier height of these three contacts were determined as $(0.59 \pm 0.01),(0.56 \pm 0.01)$ and $(0.53 \pm 0.01) \mathrm{eV}$, respectively.

From Fig. 1 we notice several interesting aspects. Firstly, at room temperature, the reverse leakage current of the control diodes are the best whereas that of the sputtered diodes are the poorest, by slightly more than a decade. Secondly, if we compare the characteristics of these diodes at $100 \mathrm{~K}$ then we see that the difference between the reverse characteristics of the three diodes has been amplified. The reverse current (at $-1 \mathrm{~V}$ ) of the sputter-deposited diode is more than four orders of magnitude higher than that of the control sample. The forward current characteristic of the sputter-deposited diode is also significantly higher than those of the other two diodes. These higher reverse currents may be the result of process-induced defects that act as generation centres. Another interesting point is that the forward characteristic of the sputter-deposited diode shows a significant increase in series resistance compared to the other diodes. This is especially noticeable for the characteristics recorded at $100 \mathrm{~K}$. This may be due to surface disorder introduced during the sputter deposition process. The control and EBD samples exhibited very similar series resistances, significantly lower than that of the sputterdeposited diode. These $I-V$ measurements clearly demonstrate that both EBD and sputter deposition resulted in degraded $I-V$ characteristics but that the sputter deposition yields the poorest diodes of the three metallization processes.

\subsection{Defects introduced by EBD of different metals}

First, we summarise what is already known for the defects introduced during EBD of Pt on Sb-doped Ge [6-8]. Note that no defects could be detected in the control SBDs fabricated by resistive deposition, indicating that the Ge is of high quality. The main defect introduced during EBD of $\mathrm{Pt}$ [7] was the E-centre (V-Sb complex) with its prominent associated electron and hole traps $\mathrm{E}_{0.38}, \mathrm{H}_{0.30}$ and $\mathrm{H}_{0.09}$, respectively. In the nomenclature used here "E" means electron trap and the number following it is the energy level of this trap below the conduction band. Similarly, " $H$ " means hole trap and the number following it is the energy level of this trap above the valence band. Note that we have not corrected these energy values to take into account the temperature dependence of the capture cross section, which has been shown to significantly change the activation energy of the E-centre [3]. Several other electron traps in lower concentrations were also detected. In the case of EBD the E-centre forms when energetic particles (originating in the region of the filament) impinge on the Ge and create vacancies at and close to the Ge surface [15]. These vacancies are mobile at room temperature and migrate into the Ge where they combine with Sb-dopant atoms to form the E-centre.
In Fig. 2, we compare the DLTS results recorded using SBDs of three different metals, namely $\mathrm{Ti}, \mathrm{Au}$ and $\mathrm{Ru}$, formed by EBD. The top three curves ((a)-(c)) are for electron traps but clearly hole injection could not be completely eliminated and therefore they still show the $\mathrm{H}_{0.30}$ trap. The lower three curves ((d)-(f)) are for hole traps and were obtained after using intentional hole injection. As was the case for $\mathrm{Pd}$ and $\mathrm{Pt}$, the most significant defect introduced is the E-centre with the traps $\mathrm{E}_{0.38}, \mathrm{H}_{0.30}$ and $\mathrm{H}_{0.09}$ associated with it [3-8]. Curve (b) also shows the presence of a defect $\mathrm{E}_{0.13}$ in a lower concentration, whereas curves (e) and (f) reveal the presence of additional hole traps, $\mathrm{H}_{0.15}$ and $\mathrm{H}_{0.18}$. The DLTS signatures of these defects were extracted from the Arrhenius plot in Fig. 3 and are summarised in Table 1.

From Fig. 2 it is further evident that the concentration of the E-centre increases from $\mathrm{Ti}$ to $\mathrm{Au}$ to $\mathrm{Ru}$. In order to explain this trend, it should be borne in mind that the defects introduced by EBD are caused by ionised particles that are accelerated from the region near the filament [15] and impinge on the Ge surface. The concentration of these particles in the residual gas in the vacuum will increase with increasing residual gas pressure as well as with increasing emission current (proportional to the filament current). In the case of Ti evaporation, the starting vacuum

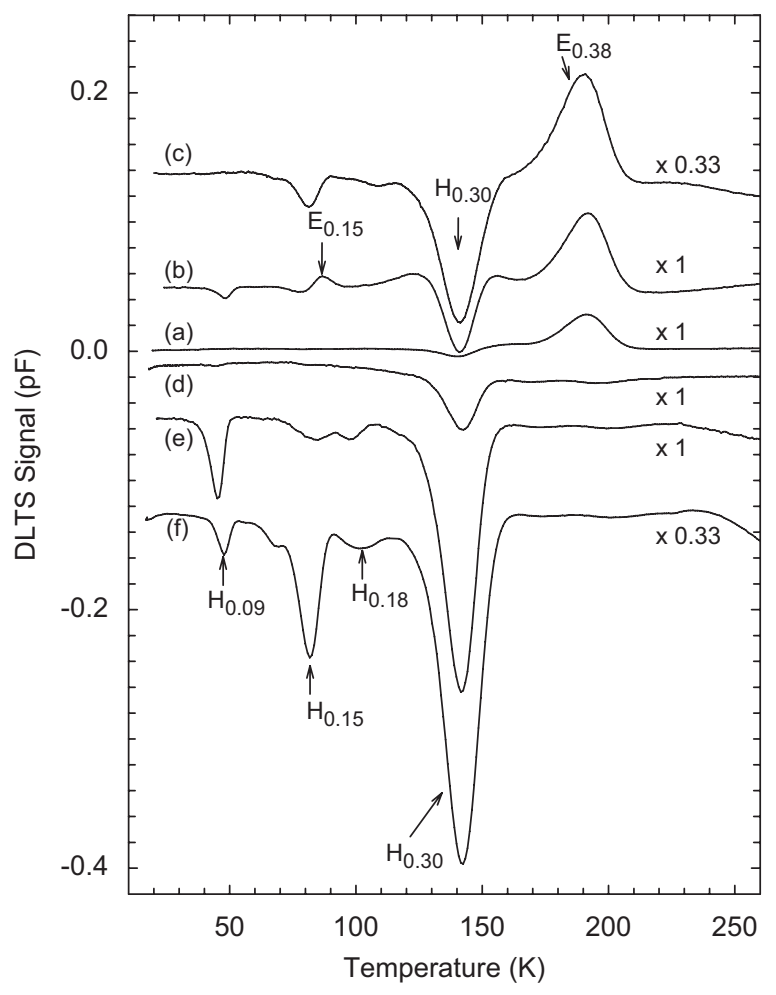

Fig. 2. DLTS spectra of Ti, Au and Ru Schottky contacts deposited by EBD to n-Ge: Curves (a), (b) and (c) are the electron-trap spectra for Ti, Au and $\mathrm{Ru}$, respectively, while curves (d), (e) and (f) are the hole-trap spectra for $\mathrm{Ti}, \mathrm{Au}$ and $\mathrm{Ru}$, respectively. These spectra were recorded using a rate window of $80 \mathrm{~s}^{-1}$ at a quiescent reverse bias of $-1 \mathrm{~V}$. For the electrontrap spectra the pulse, $V_{\mathrm{p}}$, was $0.15 \mathrm{~V}$ into forward bias. Hole-trap spectra were obtained by applying an injection pulse of $V_{\mathrm{p}}=3 \mathrm{~V}$ into forward bias. 
was more than an order of magnitude lower than for $\mathrm{Au}$ and Ru (Table 2). This means that, although the filament current was slightly higher than for Au deposition, a lower flux of particles reached the sample surface during

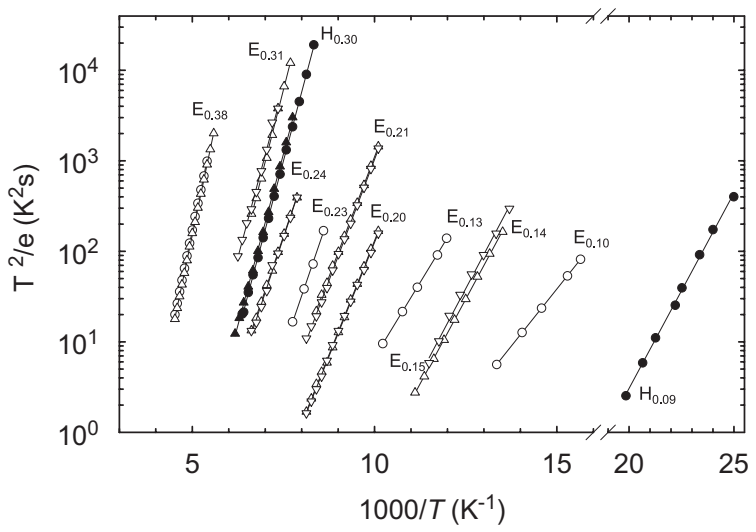

Fig. 3. Arrhenius plots for defects introduced by EBD (circles), MeV electron irradiation induced (triangles up) and sputter deposition (triangles down) in Ge. Filled symbols are for hole traps. All data were acquired using the bias and pulsing conditions defined in the caption of Fig. 2. evaporation, which in turn implies a lower level of damage, as observed in Figs. 1 and 2. When comparing the conditions for $\mathrm{Au}$ and $\mathrm{Ru}$ it can be seen from Table 2 that the vacuum during Au deposition was about the same as for $\mathrm{Ru}$ deposition. The filament current for $\mathrm{Au}$ deposition was only slightly lower than for Ru. However, if we consider the deposition rates then we notice that, due to its high melting point, the deposition rate of $\mathrm{Ru}$ is about one-twentieth of that of Au. This implies that it takes 20 times longer to deposit the same thickness of $\mathrm{Ru}$ as Au. This in turn means that the Ge surface is exposed to energetic particles for a much longer time during $\mathrm{Ru}$ deposition than during Au deposition, leading to the high concentration of defects observed for Ru metallization.

\subsection{Comparison of defects introduced by EBD and sputter deposition}

Curves (b) and (c) in Fig. 4 represent the DLTS spectra for Au Schottky diodes that were deposited by sputter deposition and EBD, respectively. Curve (d) was recorded after irradiating a resistively deposited diode with highenergy electrons at a dose of $2 \times 10^{14} \mathrm{~cm}^{-2}$. We have used Laplace DLTS to separate the signals of the $\mathrm{E}_{0.20}$ and $\mathrm{E}_{0.21}$

Table 1

Electronic properties of prominent defects introduced in n-type Ge during sputter and electron beam deposition of Schottky contacts, and by MeV electron irradiation

\begin{tabular}{|c|c|c|c|c|c|c|c|c|}
\hline \multicolumn{4}{|c|}{ Sputter deposition } & \multicolumn{4}{|c|}{ MeV electron irradiation } & \multirow[t]{2}{*}{ Similar defects/defect ID } \\
\hline Defect & $E_{\mathrm{T}}(\mathrm{eV})( \pm 0.01)$ & $\sigma_{\mathrm{a}}\left(\mathrm{cm}^{2}\right)( \pm 10 \%)$ & $T_{\text {peak }}{ }^{\mathrm{a}}(\mathrm{K})$ & Defect & $E_{\mathrm{T}}(\mathrm{eV})$ & $\sigma_{\mathrm{a}}\left(\mathrm{cm}^{2}\right)$ & $T_{\text {peak }}{ }^{\mathrm{a}}(\mathrm{K})$ & \\
\hline $\mathrm{ES}_{0.14}$ & $E_{\mathrm{C}}-0.14$ & $5.5 \times 10^{-15}$ & 78 & $\mathrm{E}_{0.15}$ & $E_{\mathrm{C}}-0.15$ & $2.8 \times 10^{-14}$ & 77 & $\mathrm{E}_{0.13^{\mathrm{b}}}, \mathrm{Sb}$ and I related ${ }^{\mathrm{c}}$ \\
\hline $\mathrm{ES}_{0.20}$ & $E_{C}-0.20$ & $3.7 \times 10^{-14}$ & 100 & $\mathrm{E}_{0.20}$ & $E_{\mathrm{C}}-0.20$ & $1.4 \times 10^{-14}$ & 100 & $\mathrm{E}_{0.19}{ }^{\mathrm{c}}, \mathrm{Sb}$ and I related ${ }^{\mathrm{c}}$ \\
\hline $\mathrm{ES}_{0.21}$ & $E_{\mathrm{C}}-0.21$ & $2.0 \times 10^{-14}$ & 109 & $\mathrm{E}_{0.21}$ & $E_{\mathrm{C}}-0.21$ & $3.6 \times 10^{-14}$ & 109 & $\mathrm{E}_{0.21}{ }^{\mathrm{c}}, \mathrm{Sb}$ related? ${ }^{\mathrm{c}}$ \\
\hline $\mathrm{ES}_{0.24}$ & $E_{\mathrm{C}}-0.24$ & $3.3 \times 10^{-15}$ & 131 & $\mathrm{E}_{0.24}$ & $E_{\mathrm{C}}-0.24$ & $2.5 \times 10^{-15}$ & 131 & 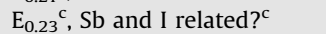 \\
\hline $\mathrm{ES}_{0.31}$ & $E_{\mathrm{C}}-0.31$ & $1.5 \times 10^{-14}$ & 151 & $\mathrm{E}_{0.31}$ & $E_{\mathrm{C}}-0.31$ & $5.0 \times 10^{-14}$ & 150 & $\mathrm{E}_{0.29}{ }^{\mathrm{c}} ?, V_{2}{ }^{\mathrm{c}} ?$ \\
\hline \multicolumn{9}{|c|}{ Electron beam deposition } \\
\hline $\mathrm{E}_{0.10}$ & $E_{\mathrm{C}}-0.10$ & $3.7 \times 10^{-16}$ & 65 & & & & & \\
\hline $\mathrm{E}_{0.13}$ & $E_{C}-0.13$ & $1.9 \times 10^{-16}$ & 85 & & & & & \\
\hline $\mathrm{E}_{0.23}$ & $E_{C}-0.23$ & $3.4 \times 10^{-14}$ & 116 & & & & & \\
\hline $\mathrm{E}_{0.38}$ & $E_{C}-0.38$ & $1.0 \times 10^{-14}$ & 191 & $\mathrm{E}_{0.38}$ & $E_{\mathrm{C}}-0.38$ & $1.1 \times 10^{-14}$ & 191 & $\mathrm{E}_{0.377^{\mathrm{b}}}, \mathrm{E}_{0.37^{\mathrm{c}}}, \mathrm{V}-\mathrm{Sb}(--/-)^{\mathrm{b}, \mathrm{c}}$ \\
\hline $\mathrm{H}_{0.09}$ & $E_{\mathrm{V}}+0.09$ & $2.1 \times 10^{-13}$ & 47 & & & & & \\
\hline $\mathrm{H}_{0.15}$ & $E_{\mathrm{V}}+0.15$ & $7.1 \times 10^{-14}$ & 82 & & & & & \\
\hline $\mathrm{H}_{0.18}$ & $E_{\mathrm{V}}+0.18$ & $3.5 \times 10^{-14}$ & 97 & & & & & \\
\hline $\mathrm{H}_{0.27}$ & $E_{\mathrm{V}}+0.27$ & $2.4 \times 10^{-13}$ & 133 & & & & & \\
\hline $\mathrm{H}_{0.30}$ & $E_{\mathrm{V}}+0.30$ & $6.2 \times 10^{-13}$ & 141 & $\mathrm{H}_{0.30}$ & $E_{\mathrm{V}}+0.30$ & $3.66 \times 10^{-13}$ & 142 & $\mathrm{H}_{0.307^{b}}, \mathrm{H}_{0.30^{c}}, \mathrm{~V}-\mathrm{Sb}(-/ 0)^{\mathrm{b}}$ \\
\hline
\end{tabular}

The error margins the value of $E_{\mathrm{T}}$ lie in the third digit after the decimal point whereas that for $\sigma$ is less than $10 \%$ of its value.

a Peak temperature at a rate window of $80 \mathrm{~s}^{-1}$.

b See Ref. [3].

c See Ref. [2].

Table 2

Electron beam deposition parameters and conditions for different metal Schottky contacts

\begin{tabular}{|c|c|c|c|c|c|}
\hline Metal & $\begin{array}{l}\text { Melting } \\
\text { point }\left({ }^{\circ} \mathrm{C}\right)\end{array}$ & $\begin{array}{l}\text { Thickness } \\
(\mathrm{nm})\end{array}$ & $\begin{array}{l}\text { Deposition } \\
\text { rate }(\mathrm{nm} / \mathrm{s})\end{array}$ & $\begin{array}{l}\text { EB filament } \\
\text { current }(\mathrm{mA})\end{array}$ & $\begin{array}{l}\text { Starting vacuum } \\
\text { (mbar) }\end{array}$ \\
\hline $\mathrm{Ti}$ & 1660 & 100 & 0.4 & 75 & $2 \times 10^{-6}$ \\
\hline $\mathrm{Au}$ & 1064 & 200 & 0.5 & 60 & $5 \times 10^{-5}$ \\
\hline $\mathrm{Ru}$ & 2250 & 50 & 0.02 & 70 & $6 \times 10^{-5}$ \\
\hline
\end{tabular}




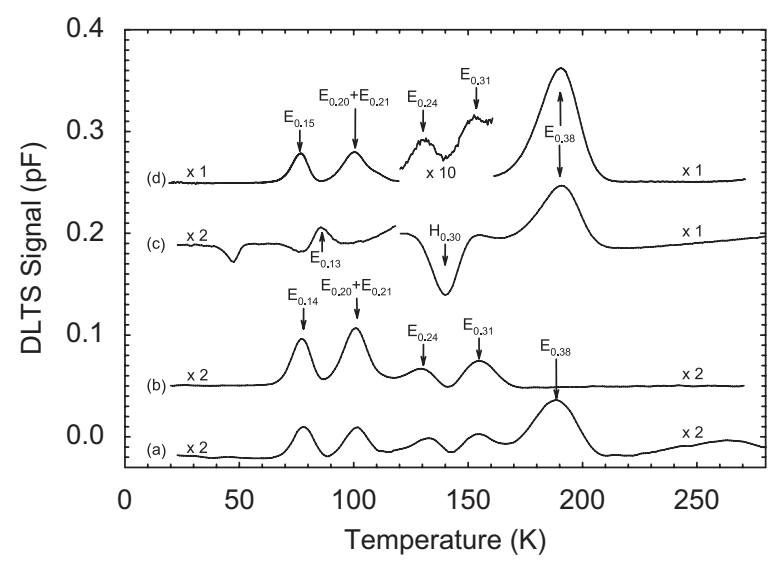

Fig. 4. DLTS spectra of Au Schottky contacts on n-Ge: Curves (a), (b) and (c) are the spectra for a sputter-deposited Au contact, a Au contact deposited by EBD and an electron-irradiated control contact, respectively. These spectra were recorded using a rate window of $80 \mathrm{~s}^{-1}$ at a quiescent reverse bias of $-1 \mathrm{~V}$. For the electron-trap spectra the pulse, $V_{\mathrm{p}}$, was $0.15 \mathrm{~V}$ into forward bias.

of electron-irradiated samples. As described above, the E-centre is the only defect that is introduced by both EBD and high-energy electron irradiation. Curve (b) shows that sputter deposition introduced several electron traps: $\mathrm{E}_{0.14}$, $\mathrm{E}_{0.20}, \mathrm{E}_{0.21}, \mathrm{E}_{0.24}$ and $\mathrm{E}_{0.31}$. However, the main electron trap introduced by EBD and electron irradiation, the E-centre, is not present in sputter-deposited diodes. Also, unlike in previous studies of high-energy electron-irradiated Ge and electron beam-deposited (EBD) Schottky diodes [6,7], we could not detect any hole traps in the sputterdeposited contacts studied here, even when applying a strong forward bias. However, after irradiating the sputter-deposited contacts with $\mathrm{MeV}$ electrons the $\mathrm{E}_{0.38}$ trap associated with the E-centre could be clearly observed (curve (a) of Fig. 4). This means that sputter deposition by itself, in our sputter equipment and under our deposition conditions, does not introduce the E-centre. It is important to point out that the E-centre has been observed by Simoen et al. [10] after sputter deposition of Pt in a different sputter system.

The fact that the E-centre is not observed after sputter deposition in our system may imply that our sputter process does not introduce a sufficient number of single vacancies at and close to the surface that can diffuse into the $\mathrm{Ge}$ and combine with $\mathrm{Sb}$ ions to form $\mathrm{V}-\mathrm{Sb}$, as in the case of EBD. It should be realised that most of the damage that we observe after sputter deposition is caused by backscattered neutral Ar ions that, for the sputter conditions used here, have a maximum energy of approximately $700 \mathrm{eV}$ of RF power [9]. From TRIM [14] modelling we have found that the range and straggle of these ions are 2.1 and $1.2 \mathrm{~nm}$, respectively. In the first $3 \mathrm{~nm}$ each ion deposits on average $20 \mathrm{eV} / \mathrm{nm}$ in to the Ge lattice and produces, on average, 5 vacancies/nm. This implies that defects larger than the single vacancy, e.g. divacancy and vacancy or interstitial clusters, can be formed. Whereas vacancy clusters, such as the divacancy, are stable at room temperature [2], interstitial clusters, by nature, are not very stable. It is therefore conceivable that when they break up, interstitials are injected into the Ge during sputter deposition. Based on this we speculate that the defects we observe after sputter deposition are related to interstitial-impurity complexes (e.g. I-Sb) or vacancy or interstitial clusters, or complexes of these clusters with impurities. The signature of $E_{0.31}$ is close to that reported for the divacancy ( $E_{0.29}$ [ [2], whereas the signatures of $\mathrm{E}_{0.14}, \mathrm{E}_{0.20}$ and $\mathrm{E}_{0.21}$ are close to that of the $E_{0.13}, E_{0.19}$ and $E_{0.23}$ proposed to be related to $\mathrm{Sb}$ and the Ge interstitial [2].

\subsection{Annealing of the metallization-induced defects}

We have previously investigated the thermal stability of the defects introduced by EBD of Pt contacts by isochronal annealing in argon (Fig. 5) [7]. Only after annealing at $225^{\circ} \mathrm{C}$ could the $\mathrm{E}_{0.38}$ and $\mathrm{H}_{0.30}$ levels no longer be detected. This is slightly higher than the $175-200{ }^{\circ} \mathrm{C}$ reported in Ref. [3] for removing the E-centre. However, it should be borne in mind that the annealing in Ref. [3] was under zero bias where most of the E-centres are filled with electrons. In our case, although we annealed at zero bias, the E-centres are very close to the surface and hence the levels of most of them are above the Fermi level. It has been reported that reverse bias annealing (E-centre level above the Fermi level) impedes the annealing of E-centres [2]. During annealing the concentration of $\mathrm{H}_{0.26}$ increased up to $200-225^{\circ} \mathrm{C}$, rendering it the most prominent defect, and then it annealed out at $350^{\circ} \mathrm{C}$. At this temperature all the defects introduced during EBD were removed.

We have also previously investigated the thermal stability of the defects introduced by sputter deposition of Au contacts by isochronal annealing in argon [9]. After annealing at $150{ }^{\circ} \mathrm{C}$ the $\mathrm{E}_{0.14}, \mathrm{E}_{0.20}$ and $\mathrm{E}_{0.24}$ levels could no longer be detected but the concentration of $\mathrm{E}_{0.31}$ increased by about a factor of two. Annealing at $200{ }^{\circ} \mathrm{C}$ reduced the

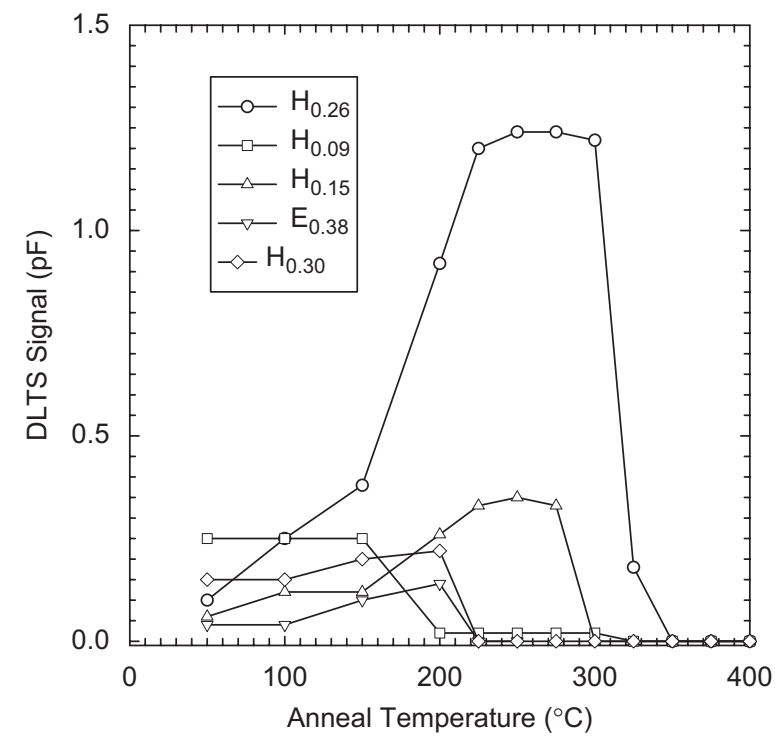

Fig. 5. Isochronal annealing ( 20 min periods) of the most prominent defects introduced by EBD in $n-G e[8]$. 
concentrations of $\mathrm{E}_{0.21}$ and $\mathrm{E}_{0.31}$ by $10 \%$ and $30 \%$, respectively, and annealing at $250{ }^{\circ} \mathrm{C}$ removed these defects completely, and no sputter deposition-induced defects could be detected any more. After annealing at $300{ }^{\circ} \mathrm{C}$, no additional defects, i.e. no "second generation" defects could be observed, indicating that the sputter-deposition-induced defects did not reconstruct during annealing to form larger defects or different defect complexes.

\section{Summary and conclusions}

The $I-V$ measurements demonstrated that both EBD and sputter deposition resulted in degraded $I-V$ characteristics, but that sputter deposition yields the poorest diodes of the two metallization methods. The higher forward and reverse currents of Au Schottky contacts formed by sputter deposition and EBD as compared to resistively deposited Au contacts is most probably the result of process-induced defects that act as generation centres. Also, the sputter-deposited diode shows a significant increase in series resistance compared to the other diodes. This may be due to surface disorder introduced during the sputter deposition process.

Our DLTS results revealed that the main defect introduced during EBD has the same electronic properties as that of the $\mathrm{V}-\mathrm{Sb}$ complex, or E-centre, introduced during highenergy electron irradiation of Ge. EBD also introduced several defects that are not introduced by electron irradiation, speculated to be higher-order vacancy clusters and complexes thereof with impurities. We show that the concentrations of the most prominent EBD-induced defect, the $\mathrm{V}-\mathrm{Sb}$ centre, depended on the metal deposited by EBD via the melting point of the metal and the influence thereof on the vacuum during metallization: in general, low melting point metals resulted in less EBD damage. All the defects introduced by sputter deposition have also been observed after high-energy electron irradiation, but the $\mathrm{V}-\mathrm{Sb}$ complex was not observed after sputter deposition. Annealing at 350 and $250^{\circ} \mathrm{C}$ in Ar removed the defects introduced during EBD and sputter deposition, respectively, and annealing at higher temperatures did not introduce any new defects.
The role of these electron beam deposition and radiation-induced defects in optimising device performance for specific applications of Ge diodes will have to be carefully examined in order to ensure optimum device performance.

\section{Acknowledgements}

The authors gratefully acknowledge financial support of the South African National Research Foundation. The Laplace DLTS software and hardware used in the research was kindly provided by A.R. Peaker (Centre for Electronic Materials Devices and Nanostructures, University of Manchester) and L. Dobaczewski (Institute of Physics, Polish Academy of Sciences).

\section{References}

[1] Germanium silicon: physics and materials. In: Hull R, Bean JC, editors. Semiconductors and semimetals, vol. 56. San Diego: Academic Press; 1999.

[2] Fage-Pedersen J, Nylandsted Larsen A, Mesli A. Phys Rev B 2000;62(10):116.

[3] Markevich VP, Peaker AR, Litvinov VV, Emstev VV, Murin LI. J Appl Phys 2004;95:4078.

[4] Markevich VP, Hawkins ID, Peaker AR, Emstev KV, Emstev VV, Litvinov VV, et al. Phys Rev B 2004;70:235213-21.

[5] Markevich VP, Hawkins ID, Peaker AR, Litvinov VV, Dobaczewski L, Lindström JL. Appl Phys Lett 2002;81:1821.

[6] Auret FD, Meyer WE, Coelho SMM, Hayes M. Appl Phys Lettt 2006;88:242110.

[7] Auret FD, Meyer WE, Coelho SMM, Hayes M, Nel JM. Mater Sci Semiconductor Process 2006;9:576-9.

[8] Auret FD, Coelho SMM, Hayes M, Meyer WE, Nel JM. Phys Status Solidi (a) 2008;205(1):159-61.

[9] Auret FD, Coelho S, Meyer WE, Nyamhere C, Hayes M, Nel JM. J Electron Mater 2007;36(12):1604.

[10] Simoen E, Opsomer K, Claeys C, Maex K, Detavernier C, Van Meirhaegh RL, et al. Appl Phys Lett 2006;89:202114.

[11] Myburg G, Auret FD. J Appl Phys 1992;71:6172.

[12] Sawko DC, Bartko J. IEEE Nucl Sci 1983;30:1756.

[13] Dobaczewski L, Kaczor P, Hawkins ID, Peaker AR. J Appl Phys 1994;76:194

[14] Dobaczewski L, Peaker AR, Bonde Nielsen K. J Appl Phys 2004;96: 4689.

[15] Christensen C, Petersen JW, Nylandsted Larsen A. Appl Phys Lett 1992;61:1426. 